\title{
Crescimento da PTF segundo tamanho de estabelecimentos rurais na região Sudeste, de 1985 a 2006
}

\author{
Farm size and TFP Growth in the Southeast region, \\ from 1985 to 2006
}

\author{
Nicoli Carolini de Lázari $^{1}$ (D) Marcelo Marques de Magalhães ${ }^{1}$
}

Resumo: O objetivo deste estudo é medir o crescimento da Produtividade Total dos Fatores (PTF) segundo o tamanho dos estabelecimentos rurais na região Sudeste entre os censos agropecuários de 1985, 1995/96 e 2006, assim como decompor o crescimento da PTF em mudança tecnológica e na eficiência técnica. A metodologia está baseada na análise de fronteira estocástica de produção. Os dados são representativos para os municípios da região Sudeste, considerando-se cinco classes de área: 0-5 ha, 5-20 ha, 20-100 ha, 100-500 ha, 500 ha e mais. Observou-se crescimento de PTF na região Sudeste, mas foi heterogêneo entre os tamanhos de estabelecimentos. As últimas classes de área, de 100-500 ha e 500 ha e mais, alcançaram maior crescimento de PTF do que as três primeiras (0-5 ha, 5-20 ha e 20-100 ha). Entretanto, todas as classes de área apresentaram aumento de ineficiência técnica.

Palavras-chave: eficiência técnica, fronteira estocástica, produtividade total dos fatores.

Abstract: The aim of this paper is to measure the Total Factor Productivity (TFP) growth by farm size in Southeast, from 1985, 1995/96 and 2006 agricultural census, as well as to decompose TFP change into its components, technological change and technical efficiency change. The methodology is based on stochastic frontier analysis. Data is aggregated at the municipality level into five size classes: 0-5 ha, 5-20 ha, 20-100 ha, 100-500 ha, and 500 ha and above. It was observed TFP growth in the Southeast; however, it was heterogeneous across size classes. The last size classes, of 100-500 ha and above 500 ha, achieved higher TFP growth than the first three classes (0-5 ha, 5-20 ha and 20-100 ha). However, all size classes had technical inefficiency increased.

Key-words: technical efficiency, stochastic frontier analysis, total factor productivity.

Classificação JEL: O30, Q12.

Data de submissão: $1^{\circ}$ de fevereiro de 2017. Data de aceite: 27 de maio de 2018.

1. Faculdade de Ciências e Engenharia, Universidade Estadual Paulista (UNESP), Tupã (SP), Brasil. E-mail: nicolilazari@gmail.com; marcelo.magalhaes@unesp.br 


\section{Introdução}

O crescimento da produtividade é importante para o aumento do bem-estar dos produtores, para o crescimento econômico do País e para o fornecimento de alimentos (Gasques et al., 2012). Com projeção até 2030 de aumento populacional e elevação na demanda por alimentos, tem-se a necessidade de ganhos de produtividade. Em países menos desenvolvidos, em períodos de baixo ou nenhum crescimento de produtividade, não houve melhora na renda e não houve redução de pobreza e fome (World Bank, 2016).

Entretanto, existem barreiras que limitam o crescimento da produtividade. A falta de assistência técnica e o difícil acesso à educação, por exemplo, originam ineficiências e impedem ganhos de produtividade. Os formuladores de políticas, se conhecedores das reais necessidades, podem direcionar as políticas de forma adequada (Barrett, 1997).

Segundo Gasques et al. (2014), a produção agropecuária cresceu no Brasil à taxa de 4,71\% entre 2000 e 2012, e o uso dos fatores de produção cresceu à uma taxa expressivamente menor, $0,62 \%$. Conforme os autores, $\mathrm{o}$ uso dos fatores de produção terra e mão de obra tiveram taxas de crescimento negativas. Notou-se aumento da produtividade do capital $(2,69 \%)$, da produtividade da terra $(3,82 \%)$ e da produtividade da mão de obra $(3,37 \%)$. Portanto, a maior parte do crescimento do produto agrícola pode ser justificada por ganhos de produtividade.

A disponibilidade de crédito, o que dá suporte a produtores agrícolas frente à sazonalidade desta produção e ao lento retorno financeiro em alguns casos, permite a ampliação da produção, a adoção de novas tecnologias e o acesso aos fatores de produção, segundo Buainain et al. (2014). Dessa forma, afeta os ganhos de produtividade do setor.

Um aumento de $1 \%$ na disponibilidade de crédito pode gerar elevação de $0,25 \%$ na produtividade, conforme Gasques et al. (2012). Além do crédito, os autores destacaram os gastos com pesquisa e o aumento nas exportações como fontes de alta na produtividade total dos fatores (PTF). $\mathrm{O}$ avanço de $1 \%$ nos gastos com pesquisas levaria a um aumento de $0,35 \%$ na PTF. A pesquisa promove o desenvolvimento de novas práticas e tecnologias.

Ainda que a agricultura brasileira apresente ganhos de produtividade, é afetada negativamente por falhas existentes no País, as quais podem impedir maiores ganhos. Conforme Buainain et al. (2014), políticas públicas buscam amenizar ou solucionar estas falhas, que muitas vezes estão ligadas à disponibilidade de pesquisa voltada à agricultura, à escolaridade e, principalmente, à infraestrutura. Os autores mencionam a inexistência de coordenação entre os agentes públicos, responsáveis pela formulação de políticas e estratégias de desenvolvimento para o País, como um impedimento de melhores resultados das políticas implantadas.

Embora a produtividade da agricultura tenha crescido, esse crescimento ocorreu de forma heterogênea entre regiões e estados. Segundo estudo realizado por Ávila et al. (2013), enquanto a produtividade da agropecuária de Mato Grosso cresceu $8,36 \%$ ao ano entre 1975 e 2006, a produtividade do Paraná e de Rondônia 
registrou aumento de 1,42\% e 3,59\% ao ano. Conforme os autores, a produtividade de estados de uma mesma região também cresceu a taxas distintas, como Espírito Santo e Rio de Janeiro, com 5,33\% e 1,41\%.

O crescimento de produtividade também foi consistente dentre as regiões do Brasil, porém heterogêneo, conforme Ávila et al. (2010). Eles utilizaram o índice de Tornqvist para obter as medidas de crescimento de produtividade. As regiões Centro-Oeste e Sudeste alcançaram as maiores taxas de crescimento de produtividade e a região Norte, a menor.

Conforme apresentado, houve aumento de produtividade agrícola, que ocorreu de maneira heterogênea entre as regiões e os estados brasileiros. Observou-se, ainda, que diversas fontes limitam ou estimulam o crescimento da produtividade. Quando um nível mais desagregado de análise é considerado, como os diferentes tamanhos de estabelecimentos, como ocorre o crescimento de produtividade? Quais as fontes que limitam ou estimulam o crescimento de produtividade dos diferentes tamanhos de estabelecimentos?

Este trabalho busca avançar no estudo da PTF da agricultura brasileira, desdobrando as estimativas obtidas em nível agregado, segundo o tamanho dos estabelecimentos rurais. Ao mesmo tempo, busca-se decompor o crescimento dessa PTF a fim de conhecer a principal fonte de crescimento da produtividade, notadamente para os diferentes tamanhos de estabelecimentos.

Portanto, o objetivo deste trabalho é medir o crescimento da produtividade total dos fatores (PTF) conforme o tamanho dos estabelecimentos rurais na região Sudeste entre os censos agropecuários de 1985, 1995/96 e 2006. Como consequência, será possível decompor o crescimento da PTF em mudança tecnológica e na eficiência técnica.

Diante do exposto, a hipótese deste trabalho é que exista heterogeneidade no crescimento da PTF segundo o tamanho dos estabelecimentos rurais na região Sudeste, e que distintas fontes expliquem essa heterogeneidade.

Com dados do último censo agropecuário, 2006, observou-se que a região Sudeste representou a maior parcela do valor da produção agropecuária do País, $32,4 \%$. Em seguida, a região Sul representou $25,8 \%$, a região Centro-Oeste, $18,4 \%$, o Nordeste, $17,8 \%$ e o Norte, $5,5 \%$. A região Sudeste, por ter grande representatividade em relação ao valor da produção do Brasil e, conforme Kageyama (2008) e Figueiredo \& Corrêa (2006), ser uma das regiões que teve um processo de modernização mais rápido e maior uso de tecnologias, foi selecionada para o estudo.

\section{Revisão bibliográfica: estudos sobre produtividade agrícola}

A produtividade é definida pela razão entre o produto obtido e os fatores de produção utilizados. Segundo FAO (Food and Agriculture Organization of the United Nations, 2000), a produtividade parcial é muito útil em comparações entre duas ou mais lavouras. Porém, há limitação: a variação na produtividade pode ser decorrente da variação de outros fatores de produção que não são considerados na medida de produtividade parcial. Por ser uma medida mais abrangente, este estudo considera a razão entre o produto e todos os fatores de produção utilizados, a chamada produtividade total dos fatores.

Moreira et al. (2007) destacaram a importância da utilização da medida de PTF para comparações entre diferentes tamanhos de produtores, como é o caso do presente estudo. $O$ trabalho desses autores mostrou que o uso da produtividade parcial pode levar a resultados extremamente diferentes, que ignoram os efeitos dos demais fatores de produção. Com o uso das duas medidas de produtividade, os autores evidenciaram que os menores produtores tiveram a maior produtividade da terra, mas a menor PTF.

O trabalho de Bragagnolo \& Barros (2015) mostrou que a modernização da agricultura e a introdução de novas tecnologias contribuíram para o aumento da produtividade e do produto agrícola. $\mathrm{O}$ aumento no uso dos fatores de produção também afeta o produto. Os autores apontaram que, entre os fatores de produção, o capital gera o maior efeito positivo sobre o produto. De forma contrária, a mão de obra provoca o menor efeito.

Conforme estudo realizado por Helfand et al. (2015), as regiões Norte e Nordeste alcançaram maior crescimento de PTF entre 1985 e 2006. Já as regiões Sudeste e Sul tiveram as menores taxas de crescimento. Essas regiões, que representam grande parcela do valor da produção agropecuária, podem ter atingido maior grau de modernização e maior produtividade em períodos anteriores na comparação com outras regiões, como Norte e Nordeste. 
Kageyama (2008) mostrou que boa parte dos estados das regiões Sul, Sudeste e Centro-Oeste é mais desenvolvida. Essas regiões exibem maior PIB per capita, melhor nível de escolaridade e acesso mais fácil à comunicação, comparativamente a alguns estados das regiões Norte e Nordeste. A possibilidade de alcançar maior desenvolvimento rural não é a mesma dentre as regiões. Estados de regiões com agricultura mais desenvolvida, segundo Figueiredo \& Corrêa (2006), como Sudeste, Sul e Centro-Oeste, foram responsáveis pela maior parcela de máquinas e tratores vendidos em 2002. Alguns estados do Nordeste apresentaram a menor utilização de insumos e tecnologias.

Embora tratem de citricultores do estado de São Paulo, Carrer \& Souza Filho (2016) identificaram que os estabelecimentos mais eficientes utilizam mais máquinas e insumos do que mão de obra, e que a ineficiência verificada entre esses citricultores pode ser reduzida pela melhor utilização dos fatores de produção.

Gasques et al. (2004) também abordaram o uso dos fatores de produção e o crescimento da PTF da agricultura brasileira, que alcançou 3,30\% ao ano entre 1975 e 2002. Conforme os autores, o índice de produto cresceu mais do que $160 \%$, enquanto o índice de insumos cresceu pouco mais de $20 \%$ no período. Com a redução no uso dos fatores de produção, observou-se crescimento, principalmente da produtividade parcial da terra, que foi responsável pela maior parte do aumento da PTF.

Além de estudar a produtividade e a eficiência da agropecuária, alguns autores utilizaram métodos que permitiram a decomposição do crescimento da produtividade, como Rada \& Buccola (2012) e Bragagnolo et al. (2010). No trabalho dos últimos autores, o crescimento da produtividade foi desigual entre os estados brasileiros.

Autores que utilizam métodos que permitem a mensuração da PTF e a decomposição de seu crescimento frequentemente utilizam, além dos fatores de produção, variáveis que afetam a eficiência e a produtividade. A adição dessas variáveis busca retirar o efeito destas da medida estimada. Variáveis associadas ao clima, como temperatura e precipitação médias, foram utilizadas no modelo estimado por Lachaud et al. (2015). Assunção \& Chein (2016) também estudaram a relação entre produtividade e variáveis climáticas.

Assim como as variáveis de clima, as variáveis de solo afetam a produtividade. Vicente (2004) utilizou variáveis que pudessem afetar a eficiência das lavouras, como o nível de irrigação e a qualidade do solo. Moreira et al. (2007), ao estudarem as diferenças de produtividade no Brasil, utilizaram tanto variáveis de clima e solo como variáveis de custo de transporte, assistência técnica e crédito. Da mesma forma, elas podem afetar a produtividade e explicar possíveis disparidades. Magalhães et al. (2011), em uma análise de eficiência dos beneficiários de um programa referente à reforma agrária, empregaram a análise de fronteira estocástica de produção e incluíram variáveis como crédito, escolaridade e assistência técnica.

Ao tratar de um menor nível de agregação dos dados, o estabelecimento rural, é possível identificar se houve crescimento de PTF somente para o pequeno, o médio ou o grande produtor. Helfand et al. (2015), por exemplo, identificaram que os menores e maiores estabelecimentos tiveram melhor desempenho se comparados aos estabelecimentos de tamanho médio no Brasil.

Moreira et al. (2007) mediram a PTF e não o crescimento da PTF, como Helfand et al. (2015), e discutiram duas possibilidades: a primeira diz respeito à relação inversa entre produtividade e tamanho de estabelecimento, em que os menores produtores, que têm menores custos de gerenciamento, seriam os mais eficientes. Por outro lado, os autores afirmam que podem existir estabelecimentos com maior eficiência em todas as classes de área. Diante disso, a relação inversa não seria verificada. A maior eficiência dependeria da adoção de tecnologia e do melhor gerenciamento do estabelecimento.

O tamanho do estabelecimento foi relacionado com duas medidas de produtividade por Moreira et al. (2007): a produtividade parcial da terra e a PTF. A produtividade parcial da terra e o tamanho de estabelecimento apresentaram uma relação inversa para as cinco regiões do Brasil. Já a relação entre PTF e tamanho de estabelecimento foi inversa em alguns casos e direta em outros.

Henderson (2015), embora tenha estudado produtores da Nicarágua, encontrou uma relação inversa entre PTF e tamanho de estabelecimento. Conforme o autor, o empenho da mão de obra familiar é maior do que o empenho da mão de obra contratada. Esta exige supervisão, que gera custos. A maior parte dos grandes estabelecimentos assume estes custos.

Por outro lado, segundo Alves et al. (2016), os menores estabelecimentos podem ter desvantagens, como maior dificuldade de acesso a insumos e crédito e maior custo de transporte. Preços relativamente mais altos 
pagos por pequenos produtores, decorrentes da menor quantidade de insumos adquirida, assim como juros relativamente mais altos, podem desestimular a expansão da produção. Os autores ressaltaram a necessidade de oferecer um ambiente que permita acesso a insumos e a novas tecnologias aos produtores.

Ali \& Deininger (2014), que também encontraram uma relação inversa entre PTF e tamanho de estabelecimento, mas, em Ruanda, buscaram controlar a heterogeneidade não observada por meio de um modelo de efeitos fixos e da adição de variáveis relativas a características do estabelecimento, como qualidade da terra, tempo de propriedade da terra e irrigação, e a características do produtor, como sexo, idade e escolaridade.

Carletto et al. (2013) não utilizaram dados do Brasil, assim como Barrett et al. (2010), mas também discutiram a relação inversa entre produtividade e tamanho de estabelecimento. Segundo os últimos autores, imperfeições de mercado podem explicar parte da relação inversa.

Helfand \& Levine (2004), por meio da DEA (Data Envelopment Analysis), estudaram a relação entre tamanho de estabelecimento e eficiência, mas somente para o Centro-Oeste do Brasil. Verificaram que a eficiência diminui conforme o aumento do tamanho da propriedade, até cerca de 1.000 a 2.000 ha e, após esse nível, passa a aumentar. As maiores propriedades podem ter acesso mais fácil a mercados e à eletricidade, o que propicia maior produtividade.

Há uma grande distinção entre os estudos que abordam os diferentes tamanhos de estabelecimentos. No trabalho de Ali \& Deininger (2014), os estabelecimentos situados em Ruanda têm, em média, 0,37 ha. No trabalho de Henderson (2015), os estabelecimentos da Nicarágua apresentaram, na média, pouco mais de 12 ha em 2005. Já no trabalho de Helfand \& Levine (2004), há estabelecimentos com mais de 5.000 ha. Neste artigo, a área do estabelecimento representativo da região Sudeste tem, em média, 835 ha. Os estabelecimentos com maiores áreas (10\% maiores) têm 2.500 ha e mais.

Melo-Becerra \& Orozco-Gallo (2017) estudaram produtores da Colômbia que operavam em diferentes condições socioeconômicas e de solo e clima. Os resultados mostraram a existência de menor eficiência entre as menores produções. Estes autores, igualmente a Alves et al. (2016), destacaram a importância da criação de políticas direcionadas principalmente às pequenas produções, políticas que proporcionem melhores condições para a tomada de decisões e para a adoção de tecnologias.
Suri (2011) destacou que produtores que poderiam ter um alto retorno da adoção de tecnologias muitas vezes não as adotam, devido principalmente ao alto custo dessa adoção. A autora esclarece que o custo de adquirir uma tecnologia é distinto entre os produtores, assim como o retorno que essa tecnologia pode oferecer.

\section{Metodologia: Fronteira Estocástica de Produção}

A fronteira de produção é derivada de uma função de produção. Esta indica, segundo Aigner et al. (1977), o produto máximo resultante de uma combinação de insumos. Todavia, as firmas podem produzir menor quantidade com essa mesma combinação de insumos, estando abaixo do produto máximo estimado.

A fronteira de produção representa os produtores mais eficientes e, conforme Aigner et al. (1977), a diferença entre a produção observada das firmas e a fronteira estimada pode ser explicada não somente pela existência de ineficiência, mas também por efeitos aleatórios (como sorte e clima) e erros de especificação do modelo. Desta maneira, o termo de erro do modelo de fronteira estocástica é dividido em dois componentes, um referente à ineficiência e outro ao resíduo, que compreende efeitos aleatórios e erros de especificação.

Battese \& Coelli (1992) sugerem a aplicação do modelo de fronteira estocástica para dados em painel. Com informações de 1975/76 a 1984/85, estudaram a eficiência técnica de agricultores da Índia. Neste artigo, os dados em painel utilizados abrangem três censos agropecuários: 1985, 1995/96 e 2006.

O modelo de fronteira estocástica representado pela equação 1, conforme Battese \& Coelli (1992), permite estimar a máxima produção, assim como a ineficiência técnica das firmas, e admite que a ineficiência varie ao longo do tempo.

$\mathrm{Y}_{\mathrm{it}}=f\left(\mathrm{x}_{\mathrm{it}} ; \beta\right) \exp \left(\mathrm{V}_{\mathrm{it}}-\mathrm{U}_{\mathrm{it}}\right)$

$Y_{i t}$ é a produção; $x_{i{ }^{\prime}}$ os fatores de produção; $\beta$, os parâmetros a serem estimados; $V_{i t^{\prime}}$ o resíduo referente aos efeitos aleatórios e erros de especificação; $U_{i t^{\prime}}$ a ineficiência; os subscritos referem-se à firma $i$ e ao tempo $t$. $O$ segundo componente do termo de erro, $U_{i t^{\prime}}$ é representado pela Equação 2. 
$\mathrm{U}_{\mathrm{it}}=\mathrm{U}_{\mathrm{i}} \exp [-\eta(\mathrm{t}-\mathrm{T})]$

$\eta$ é um parâmetro a ser estimado, $t$, o tempo e $T$, o tempo final. Segundo Battese \& Coelli (1992), a ineficiência pode diminuir (se $\eta>0$ ), aumentar $($ se $\eta<0$ ) ou permanecer constante (se $\eta=0$ ) conforme o tempo. Quando $\eta>0$, nota-se um incremento na eficiência técnica das firmas.

A eficiência técnica (technical efficiency - TE), medida derivada do modelo de fronteira estocástica de produção, é a relação entre a produção observada (y) e o valor da fronteira estocástica $\left(\mathrm{y}^{*}\right)$ das firmas, como a equação 3 (Coelli et al., 2003).

$\mathrm{TE}=\frac{\mathrm{Y}_{\mathrm{i}}}{\mathrm{Y}_{\mathrm{i}}^{*}}=\frac{f\left(\mathrm{x}_{\mathrm{i}} ; \beta\right) \exp \left(\mathrm{V}_{\mathrm{i}}-\mathrm{U}_{\mathrm{i}}\right)}{f\left(\mathrm{x}_{\mathrm{i}} ; \beta\right) \exp \left(\mathrm{V}_{\mathrm{i}}\right)}=\exp \left(-\mathrm{U}_{\mathrm{i}}\right)$

A fronteira estocástica de produção pode apresentar a forma funcional translog, que possibilita interação entre os fatores de produção e entre estes e a tendência t. Cobb-Douglas é uma forma mais simples, exige menor número de parâmetros a serem estimados em relação à translog e assume elasticidade de substituição entre os fatores igual a um (Conceição, 2004; Kumbhakar et al., 2015).

Apesar de ser mais flexível, de acordo com Rada \& Buccola (2012), a translog não é adequada para análises com poucos pontos no tempo. Este trabalho considera três pontos no tempo, 1985, 1995/ 96 e 2006, o que leva à adoção da forma Cobb-Douglas. Observa-se pela equação 4 o modelo de fronteira estocástica de produção seguindo Battese \& Coelli (1992).

$$
\begin{aligned}
& \ln \mathrm{Y}_{\mathrm{it}}=\beta_{0}+\beta_{1} \ln \left(\mathrm{A}_{\mathrm{it}}\right)+\beta_{2} \ln \left(\mathrm{L}_{\mathrm{it}}\right)+ \\
& \beta_{3} \ln \left(\mathrm{I}_{\mathrm{it}}\right)+\beta_{4} \ln \left(\mathrm{K}_{\mathrm{it}}\right)+\beta_{5} \mathrm{~T}+\left(\mathrm{V}_{\mathrm{it}}-\mathrm{U}_{\mathrm{it}}\right)
\end{aligned}
$$

A estimativa de eficiência pode ser afetada pela presença de heterogeneidade não observada. O modelo de efeitos aleatórios correlacionados (Correlated Random Effects - CRE) de Mundlak (1978) considera a correlação entre as variáveis independentes e a heterogeneidade não observada. Assume-se que esta é correlacionada com a média das variáveis explicativas. O ajuste de Mundlaké inserido no modelo de fronteira estocástica de produção para dados em painel estimado nesta pesquisa.

$\mathrm{O}$ foco deste trabalho não está na PTF, mas no crescimento da PTF. Conforme Coelli et al. (2003), o crescimento da PTF pode ser encontrado por meio da soma da mudança tecnológica e mudança na eficiência técnica. Observa-se pelas equações 5 e 6 a definição desses componentes seguindo estes autores.
A mudança tecnológica (technical change - TC) é verificada pela derivada parcial do modelo estimado em relação à tendência T (Kumbhakar et al., 2015). Este componente causa um deslocamento na fronteira. A produção potencial passa a ser maior, assim como a produtividade do tempo $t 2$ em relação ao tempo $t 1$, devido à tecnologia existente no período final (O’Donnell, 2010).

$\mathrm{TC}=\left[\left(\partial \mathrm{y}_{\mathrm{t} 1} / \partial \mathrm{T}\right)+\left(\partial \mathrm{y}_{\mathrm{t} 2} / \partial \mathrm{T}\right)\right] / 2$

Para medir a mudança na eficiência técnica (technical efficiency change-TEC), considera-se a eficiência técnica estimada para períodos distintos, período $t 1$ e período t2. Conforme Kalirajan et al. (1996), observa-se mudança positiva na eficiência técnica quando a distância entre a produção observada e o valor da fronteira estocástica estimado é menor no tempo $t 2$ em comparação ao tempo $t 1$.

$\mathrm{TEC}=\mathrm{Ln}\left(\mathrm{TE}_{\mathrm{t} 2} / \mathrm{TE}_{\mathrm{t} 1}\right)$

\subsection{Dados}

O produto é formado pelo valor da produção de 39 produtos que cobrem $85 \%$ do valor total da produção, sendo 13 referentes à produção animal (animais vendidos e abatidos dos rebanhos de bovinos, bubalinos, equinos, asininos, muares, suínos, caprinos, ovinos, aves, produção de leite de vaca, de leite de cabra, produção de ovos e de lã de ovinos), 13, às lavouras permanentes (agave, banana, cacau, café, coco-da-baía, laranja, maçã, manga, mamão, maracujá, tangerina, uva mesa e uva vinho) e 13, às lavouras temporárias (abacaxi, algodão, arroz, batata, cana-de-açúcar, cebola, feijão, fumo, mandioca, milho, soja, tomate e trigo). O valor da produção foi disponibilizado pelos censos agropecuários, IBGE (Instituto Brasileiro de Geografia e Estatística, 1991, 1998, 2012). Para a deflação foi utilizado um deflator de preço implícito obtido a partir de Gasques et al. (2010).

Para formar a variável área foram consideradas as áreas (em hectares) de lavoura permanente, lavoura temporária, lavoura em descanso, pastagens naturais, terras produtivas não utilizadas e matas plantadas. Para obter o valor da área foram utilizados os preços relativos ao valor das terras de pastagens disponibilizados pela Fundação Getúlio Vargas (1985).

A mão de obra familiar compreendeu o número de pessoal ocupado com laço de parentesco com o produtor: homens de 14 anos e mais, mulheres de 14 anos e mais e total de menos de 14 anos. Dados dos censos 
agropecuários, IBGE (Instituto Brasileiro de Geografia e Estatística, 1991, 1998, 2012).

$\mathrm{O}$ valor das despesas, separado por categorias nos censos, IBGE (Instituto Brasileiro de Geografia e Estatística, 1991, 1998, 2012), foi agregado nos seguintes grupos: salários de empregados e integrantes da família, insumos na produção vegetal (adubos, corretivos, sementes e mudas e agrotóxicos), insumos na produção animal (sal, rações e medicamentos) e outras despesas.

O estoque de capital foi construído com a agregação de três componentes seguindo Helfand et al. (2015): valor das máquinas, do fluxo das lavouras permanentes e do efetivo de animais. Essa construção permite ponderar o índice médio segundo a importância relativa entre seus componentes. Dentro de cada componente do estoque de capital, tratou-se de forma distinta o peso relativo segundo os tipos de máquinas (caminhões, caminhonetes, plantadeiras, colheitadeiras e tratores), rebanhos e lavouras.

Esta estratégia permite tratar de maneira distinta o perfil de composição de capital de cada região. Na região Norte, conforme Helfand et al. (2015), o valor do efetivo de animais é responsável pela maior parcela do estoque de capital. Já para a região estudada neste artigo, Sudeste, o componente de maior peso é o valor das máquinas, com 0,50 como coeficiente de ponderação. $\mathrm{O}$ valor das lavouras foi o segundo componente com maior peso, 0,27 . O valor dos animais teve a menor participação no estoque de capital, coeficiente igual a 0,23.

Para construir o primeiro componente do estoque de capital, valor das máquinas, utilizou-se o número de máquinas e o preço médio destas em São Paulo, disponibilizado pelo Instituto de Economia Agrícola (2015). O valor das lavouras permanentes foi formado com base na produtividade média, estimada a partir dos dados dos censos, IBGE - Instituto Brasileiro de Geografia e Estatística (1991, 1998, 2012), e preços das lavouras. Com um fluxo futuro e uma taxa de $6 \%$ ao ano, obteve-se o valor presente dessas lavouras. O último componente, valor do efetivo de animais, foi formado pela quantidade disponibilizada pelos censos e preços relativos.

As demais variáveis que podem afetar a produtividade foram inclusas para controlar os efeitos fixos. A inclusão dos desvios da média de precipitação permite retirar da medida de produtividade os efeitos dos períodos anormais de baixa ou alta precipitação em relação à média. A partir de informações de precipitação mensal, calculou-se a precipitação trimestral. Com dados anteriores aos censos agropecuários de 1985, 1995/96 e 2006, foi possível obter a precipitação média de 25 anos. Os desvios da precipitação em relação à média foram separados em cinco classes de percentis: $0-20 \%$, $20-40 \%, 40-50 \%, 60-70 \%$ e $80-100 \%$. Os percentis $0-20 \%$ e $80-100 \%$ representam períodos extremos de baixa e alta precipitação em relação à média.

No grupo das variáveis de solo há três indicadores oriundos do projeto Basis / Esalq, construídos por Gerd Sparovek (2006): mecanização potencial, capacidade de drenagem do solo e fertilidade do solo. A altitude foi disponibilizada pelo IBGE (Instituto Brasileiro de Geografia e Estatística, 2005). O custo de transporte da sede municipal até a capital mais próxima para 1980, uma variável de mercado, foi disponibilizada pelo Instituto de Pesquisa Econômica Aplicada (IPEA).

As variáveis de políticas, assistência técnica e crédito foram construídas por meio de instrumentação, a fim de evitar endogeneidade. Para a assistência técnica, a instrumentação buscou prever o número de estabelecimentos atendidos em função do número de técnicos agrícolas disponível nos censos demográficos, IBGE- Instituto Brasileiro de Geografia e Estatística (1983, 1994, 2003), com defasagem de cinco anos para os censos agropecuários. Para o crédito, a instrumentação buscou prever a parcela dos estabelecimentos com acesso ao crédito rural.

A partir da regressão do número de estabelecimentos atendidos por assistência técnica, disponibilizado pelos censos agropecuários, sobre o número de técnicos ocupados em atividades agropecuárias, disponibilizado pelos censos demográficos, obteve-se o valor previsto do número de estabelecimentos atendidos por assistência técnica.

Para a variável crédito, estimou-se uma regressão do número de estabelecimentos com acesso ao crédito, disponibilizado pelos censos agropecuários, sobre o número de agências bancárias públicas, que operacionalizam contratos de crédito rural, existente no início de cada ano dos censos, conforme BACEN (Banco Central do Brasil, 2015). Utilizou-se a parcela prevista dos estabelecimentos com acesso ao crédito.

Neste trabalho considera-se a média das variáveis dos estabelecimentos agropecuários agregada em nível 
municipal, em cinco classes de área: 0-5 ha, 5-20 ha, 20-100 ha, 100-500 ha, 500 ha e mais. Portanto, todos os estabelecimentos do município são representados por cinco estabelecimentos médios, denominados como estabelecimentos representativos. As observações são ponderadas pela participação no valor da produção. O Quadro 1 sintetiza a definição das variáveis utilizadas.

As estatísticas descritivas do produto e dos fatores de produção mostraram que a média do produto cresce conforme o tamanho do estabelecimento. Deve ser destacado que a última classe de área (500 ha e mais) tem um intervalo aberto e pode abranger estabelecimentos com área muito acima de 500 ha.

Para o produto, observa-se que, na classe de área 100-500 ha, o percentil $90 \%$ é 16 vezes maior do que o percentil $10 \%$. Já na classe de área 500 ha e mais, o percentil $90 \%$ é 33 vezes maior do que o percentil 10\%. Isso corrobora o fato de que, nesta classe de área, pode existir estabelecimento com área extremamente superior a 500 ha.

A média da mão de obra não aumenta conforme o tamanho do estabelecimento, como no caso das despesas e do estoque de capital. Para as despesas, observa-se que 90\% dos estabelecimentos da menor classe de área, 0-5 ha, direcionam até R\$ 24.047 e 90\% dos estabelecimentos da quarta e quinta classe de área, 100-500 ha e 500 ha e mais, direcionam valores 13 e 244 vezes maior.

\section{Resultados e discussão}

Foram estimados dez modelos para a região Sudeste e para cada tamanho de estabelecimento. O modelo 1 é o mais simples e o modelo 10 possui, além dos fatores

Quadro 1. Construção e fonte de informação das variáveis utilizadas nos modelos estimados

\begin{tabular}{|c|c|c|c|}
\hline $\begin{array}{c}\text { Grupos de } \\
\text { variáveis }\end{array}$ & Variáveis & Fonte & Construção \\
\hline Produto & Produto & $\begin{array}{l}\text { Censos Agropecuários, IBGE (Instituto } \\
\text { Brasileiro de Geografia e Estatística, 1991, } \\
\text { 1998, 2012). }\end{array}$ & Valor da produção de 39 produtos \\
\hline \multirow{4}{*}{$\begin{array}{l}\text { Fatores de } \\
\text { Produção }\end{array}$} & Área & $\begin{array}{l}\text { Censos Agropecuários, IBGE (Instituto } \\
\text { Brasileiro de Geografia e Estatística, 1991, } \\
\text { 1998, 2012) e FGV (Fundação Getúlio } \\
\text { Vargas, 2015) }\end{array}$ & $\begin{array}{l}\text { Seis tipos de utilização de terras (em ha) } \\
\text { e preços relativos às terras de pastagens }\end{array}$ \\
\hline & Mão de obra & $\begin{array}{l}\text { Censos Agropecuários, IBGE (Instituto } \\
\text { Brasileiro de Geografia e Estatística, 1991, } \\
\text { 1998, 2012). }\end{array}$ & $\begin{array}{l}\text { Pessoal ocupado com laço de parentesco } \\
\text { com o produtor }\end{array}$ \\
\hline & Despesas & $\begin{array}{l}\text { Censos Agropecuários, IBGE (Instituto } \\
\text { Brasileiro de Geografia e Estatística, 1991, } \\
\text { 1998, 2012). }\end{array}$ & $\begin{array}{l}\text { Salários, insumos na produção vegetal e } \\
\text { animal e outras despesas }\end{array}$ \\
\hline & Estoque de capital & $\begin{array}{l}\text { Censos Agropecuários, IBGE (Instituto } \\
\text { Brasileiro de Geografia e Estatística, 1991, } \\
\text { 1998, 2012); Helfand et al. (2015); IEA } \\
\text { (Instituto de Economia Agrícola, 2015) }\end{array}$ & $\begin{array}{l}\text { Valor das máquinas, valor do efetivo de } \\
\text { animais e valor do fluxo das lavouras } \\
\text { permanentes }\end{array}$ \\
\hline \multirow{5}{*}{$\begin{array}{l}\text { Variáveis de } \\
\text { controle dos } \\
\text { efeitos fixos }\end{array}$} & Precipitação & Willmott \& Matsuura (2001) & Desvios da precipitação em relação à média \\
\hline & Solo & $\begin{array}{l}\text { Basis/Esalq - Gerd Sparovek (Sparovek } \\
\text { (2006), IBGE (Instituto Brasileiro de Geografia } \\
\text { e Estatística, 2005) }\end{array}$ & $\begin{array}{l}\text { Mecanização potencial, capacidade de } \\
\text { drenagem do solo e fertilidade do solo; } \\
\text { e altitude }\end{array}$ \\
\hline & Custo de transporte & $\begin{array}{l}\text { IPEA (Instituto de Pesquisa Econômica } \\
\text { Aplicada, 1980) }\end{array}$ & $\begin{array}{l}\text { Custo de transporte da sede municipal até } \\
\text { a capital mais próxima }\end{array}$ \\
\hline & Assistência Técnica & $\begin{array}{l}\text { Censos Agropecuários e Censos Demográficos, } \\
\text { IBGE (Instituto Brasileiro de Geografia e } \\
\text { Estatística, 1983, 1994, 2003). }\end{array}$ & $\begin{array}{l}\text { Valor previsto do número de estabelecimentos } \\
\text { atendidos por assistência técnica em função } \\
\text { do número de técnicos agrícolas }\end{array}$ \\
\hline & Crédito Rural & $\begin{array}{l}\text { BACEN (Banco Central do Brasil, 2015) } \\
\text { e Censos Agropecuários, IBGE (Instituto } \\
\text { Brasileiro de Geografia e Estatística, 1991, } \\
\text { 1998, 2012). }\end{array}$ & $\begin{array}{l}\text { Valor previsto do número de estabelecimentos } \\
\text { com acesso ao crédito em função do número } \\
\text { de agências bancárias públicas }\end{array}$ \\
\hline
\end{tabular}

Fonte: Elaborado pelos autores. 
de produção, o controle de Mundlak e variáveis que podem afetar o crescimento da produtividade.

Os coeficientes do modelo 1 para a região Sudeste são significativos ao nível de $1 \%$ (os modelos estimados para a região Sudeste estão no Apêndice A). O aumento de $10 \%$ das despesas gera um aumento de $6,27 \%$ no produto, fator de produção que provoca o maior efeito no crescimento do produto. O aumento de $10 \%$ na área e no estoque de capital também contribui para o crescimento do produto, mas em menor proporção. A mão de obra familiar teve sinal negativo. Um avanço de $10 \%$ na mão de obra leva à redução de $0,95 \%$ no produto.

Os sinais destes coeficientes eram esperados, assim como o maior coeficiente para as despesas e o menor para a mão de obra familiar. Conforme Bragagnolo \& Barros (2015), a mão de obra familiar representou entre $70 \%$ e $80 \%$ do pessoal ocupado na agricultura no período de 1970 a 2006. Os censos agropecuários apontaram que, em 1985, o número de pessoal ocupado no Brasil era 23.394.919 e, em 2006, o número caiu para 16.568.205.

Nota-se, por meio dos censos agropecuários de 1985 , 1995/ 96 e 2006, aumento de $20 \%$ no número de tratores entre 1985 e 1996, e elevação de apenas $2 \%$ entre 1996 e 2006. Embora os de menor potência representem a maior parcela dos tratores utilizados no Brasil, observa-se tendência de substituição de tratores de menos de 100 cavalos (cv) por tratores de $100 \mathrm{cv}$ e mais no período 1996-2006.

A Tabela 1 expõe o crescimento da PTF por tamanho de estabelecimentos conforme os dez diferentes modelos. O modelo 1 tem como variáveis independentes apenas os fatores de produção (área, mão de obra familiar, despesas e estoque de capital). O modelo 2 tem, além dos fatores de produção, controle por unidade da federação que considera a heterogeneidade existente entre os estados da região Sudeste. Observa-se pouca diferença entre as estimativas de crescimento da PTF resultantes desses dois modelos.

O modelo 3 considerou a correlação entre a heterogeneidade não observada e as variáveis independentes com a inclusão do ajuste de Mundlak para os efeitos fixos. Esse ajuste aparentemente tem controle relevante sobre a estimativa de crescimento da PTF nos tamanhos 5-20 ha e 20-100 ha. As medidas de crescimento da PTF dessas classes de área derivadas deste modelo foram $47 \%$ e $53 \%$ maiores do que as medidas de crescimento derivadas do modelo 2 .

Buscou-se retirar da medida de crescimento da PTF resultante dos modelos 4, 5, 6 e 7 os efeitos de clima e solo (características locais) e custo de transporte (característica de mercado). O censo agropecuário de 2006 mostrou que apenas 2,9\% da área da região Sudeste é irrigada, o que reforça a importância da precipitação. Minas Gerais tem o menor percentual de área irrigada, 1,6\% . Rio de Janeiro, São Paulo e Espírito Santo têm 4\%, 4,6\% e 7,4\% de área irrigada. Lachaud et al. (2015) utilizaram variável de precipitação e indicaram que variações no clima poderão reduzir a produtividade em mais de $2 \%$ entre 2013 e 2040.

Variáveis de solo que podem afetar a produtividade, como potencial de mecanização, capacidade de drenagem do solo, fertilidade do solo e altitude foram adicionadas posteriormente. Vicente (2004), com foco no nível de eficiência dos estados do Brasil, utilizou variáveis de clima e solo que buscam captar efeitos semelhantes aos que esta pesquisa buscou controlar.

Tabela 1. Crescimento da PTF da região Sudeste por tamanho de estabelecimentos segundo diferentes modelos, $1985-2006(\mathrm{em} \%)$

\begin{tabular}{|c|c|c|c|c|c|c|c|c|c|c|}
\hline $\begin{array}{c}\text { Região e } \\
\text { Classes de } \\
\text { área (ha) }\end{array}$ & $\mathrm{CD}$ & CD i.UF & CD CRE & $\begin{array}{l}\text { CD CRE } \\
\text { + Clima }\end{array}$ & $\begin{array}{c}\text { CD CRE } \\
\text { + Clima } \\
\text { + Solo }\end{array}$ & $\begin{array}{l}\text { CD CRE } \\
+ \text { Clima } \\
+ \text { Transp }\end{array}$ & $\begin{array}{l}\text { CD CRE } \\
\text { + Clima } \\
\text { + Solo } \\
\text { + Transp }\end{array}$ & $\begin{array}{l}\text { CD CRE } \\
\text { + Clima } \\
\text { + Política }\end{array}$ & $\begin{array}{l}\text { CD CRE } \\
\text { + Clima } \\
\text { + Solo } \\
\text { + Política }\end{array}$ & $\begin{array}{c}\text { CD CRE } \\
\text { + Clima } \\
\text { + Solo } \\
\text { + Transp } \\
\text { + Política }\end{array}$ \\
\hline & 1 & 2 & 3 & 4 & 5 & 6 & 7 & 8 & 9 & 10 \\
\hline Sudeste & 1,37 & 1,45 & 1,85 & 3,11 & 3,16 & 3,10 & 3,16 & 3,07 & 3,12 & 3,12 \\
\hline $0-5$ & 0,69 & 0,62 & 0,43 & 0,74 & 0,77 & 0,76 & 0,79 & 0,76 & 0,79 & 0,80 \\
\hline $5-20$ & 0,80 & 0,78 & 1,15 & 2,12 & 2,25 & 2,13 & 2,25 & 2,15 & 2,28 & 2,28 \\
\hline $20-100$ & 0,81 & 0,84 & 1,28 & 2,46 & 2,53 & 2,47 & 2,53 & 2,45 & 2,51 & 2,50 \\
\hline $100-500$ & 1,62 & 1,64 & 1,71 & 3,40 & 3,43 & 3,41 & 3,44 & 2,95 & 2,96 & 2,96 \\
\hline $500+$ & 1,87 & 2,02 & 2,15 & 2,74 & 2,73 & 2,75 & 2,73 & 2,77 & 2,79 & 2,81 \\
\hline
\end{tabular}

Fonte: Resultados da pesquisa.

Nota: 1. As observações foram ponderadas pela participação no valor da produção. 
Em um estudo sobre diferentes produtividades no Brasil realizado por Moreira et al. (2007), foi inserida uma variável de custo de transporte entre as demais variáveis que buscavam controlar efeitos sobre a medida de produtividade. Conforme os autores, o custo de transporte pode ajudar a explicar diferenças de produtividade e a captar custos de transação que afetam os preços dos produtos de diferentes municípios.

Desse modo, no modelo 4 foi inserida somente a variável de clima (desvios da média de precipitação), que causou diferença expressiva na medida de crescimento da PTF comparativamente à medida derivada dos modelos anteriores. As variáveis de solo (mecanização potencial, capacidade de drenagem do solo, fertilidade e altitude) foram adicionadas no modelo 5 . A inclusão destas não foi relevante como a inclusão da variável de clima.

No modelo 6 foi mantida a variável de clima e foi adicionada a variável de custo de transporte. A medida de crescimento da PTF resultante do modelo 6 foi muito próxima à medida resultante do modelo 4 . No modelo 7 foram mantidas todas as variáveis anteriores: clima, solo e custo de transporte. Para este conjunto de modelos observou-se que a introdução das variáveis de solo e de custo de transporte não foi relevante como a inclusão da variável de clima. Esses modelos fornecem estimativas próximas de crescimento da PTF.

Assunção \& Chein (2016) mostraram a importância do clima para a produção agrícola. Conforme os autores, períodos de anomalias climáticas podem reduzir a produtividade e elevar o grau de heterogeneidade entre os estados brasileiros. Para a região Sudeste, estes autores estimaram que uma redução de $0,77 \%$ na precipitação média e um aumento de 6,86\% na temperatura média provocariam queda de mais de $16 \%$ na produtividade agrícola.

Nos modelos 8, 9 e 10 foram adicionadas as variáveis de políticas públicas (assistência técnica e crédito). Autores como Magalhães et al. (2011) utilizaram variáveis de políticas em um estudo sobre eficiência. Segundo os autores, o crédito, que possibilita acesso aos fatores de produção, e a assistência técnica podem contribuir para a redução da ineficiência dos produtores estudados. No modelo 8 foram mantidas as variáveis de clima e adicionadas as de políticas. No modelo 9 foram mantidas as variáveis de clima, solo e políticas. E no modelo 10, mais completo, foram mantidas todas as variáveis: clima, solo, custo de transporte e políticas.
Esses últimos modelos têm em comum o efeito diferencial das políticas para os estabelecimentos de 100-500 ha, que tiveram estimativas de crescimento da PTF menores do que as derivadas dos modelos anteriores (4, 5, 6 e 7). A classe de área $100-500$ ha pode não ter um direcionamento de políticas apropriado como os estabelecimentos maiores têm.

O modelo 4 que tem a adição da variável de clima (desvios da média de precipitação) e o modelo 10 que tem todas as variáveis (clima, solo, custo de transporte e políticas) foram estimados com controle apenas por unidade da federação antes de serem estimados com controle de Mundlak. As estimativas derivadas dos modelos com controle por unidade da federação apresentaram pouca variação em relação às estimativas derivadas dos modelos com controle de Mundlak, exceto para a classe de área 0-5 ha. Nela, as estimativas com controle de Mundlak apresentaram variação de mais de $30 \%$. Há maior heterogeneidade nesta classe de área.

A medida de crescimento da PTF da região Sudeste passa por alterações conforme a adição de variáveis que buscam controlar primeiro efeitos locais e, posteriormente, efeitos intermediários. Porém, o comportamento do crescimento da PTF segundo o tamanho de estabelecimentos é semelhante entre os modelos.

O modelo 10 para a região Sudeste e para cada tamanho de estabelecimento, por ter controle de Mundlak e variáveis de características de clima, solo, custo de transporte e políticas, foi tido como base para os demais resultados apresentados a seguir. Observa-se, pelo modelo estimado para a região Sudeste, que a ineficiência aumentou com o tempo $(\eta<0)$. A Tabela 2 apresenta o crescimento médio anual do produto e dos fatores de produção, calculado a partir da média do valor agregado da região, e a decomposição do crescimento médio anual da PTF.

As despesas cresceram à taxa de $3,98 \%$ ao ano entre 1985-2006, fator de produção com maior taxa de crescimento. A área e a mão de obra tiveram taxas negativas de crescimento. O crescimento do produto foi maior do que o crescimento dos fatores de produção. O avanço médio anual da PTF entre 1985-2006 foi de $3,12 \%$. Supõe-se que parte do crescimento do produto seja explicada pela elevação da PTF.

Ávila et al. (2013) estimaram um crescimento de PTF de 2,67\% entre 1975 e 2006, resultado diferente do 
Tabela 2. Crescimento do produto, dos fatores de produção' ${ }^{1}$ da PTF e decomposição do crescimento da PTF², $1985-2006(\mathrm{em} \%)$

\begin{tabular}{lcccccccc}
\hline $\begin{array}{c}\text { Região e } \\
\text { Classes de } \\
\text { área (ha) }\end{array}$ & Produto & Área & $\begin{array}{c}\text { Mão de } \\
\text { Obra } \\
\text { Familiar }\end{array}$ & Despesas & $\begin{array}{c}\text { Estoque de } \\
\text { Capital }\end{array}$ & PTF & $\begin{array}{c}\text { Mudança } \\
\text { Tecnológica }\end{array}$ & $\begin{array}{c}\text { Mudança na } \\
\text { Eficiência } \\
\text { Técnica }\end{array}$ \\
\hline Sudeste & 4,40 & $-0,77$ & $-1,30$ & 3,98 & 0,23 & 3,12 & 9,55 & $-6,43$ \\
$0-5$ & 2,78 & $-0,29$ & 0,23 & 1,26 & 2,97 & 0,80 & 5,16 & $-4,36$ \\
$5-20$ & 3,89 & $-0,72$ & $-0,45$ & 3,50 & 2,17 & 2,28 & 7,94 & $-5,66$ \\
$20-100$ & 2,05 & $-1,82$ & $-1,82$ & 1,88 & 0,09 & 2,50 & 7,35 & $-4,84$ \\
$100-500$ & 4,79 & $-1,89$ & $-2,10$ & 3,31 & $-0,10$ & 2,96 & 12,00 & $-9,06$ \\
$500+$ & 5,20 & 0,00 & $-1,06$ & 5,03 & 0,05 & 2,81 & 5,68 & $-2,87$ \\
\hline
\end{tabular}

Fonte: Resultados da pesquisa.

Notas: 1 . O crescimento médio anual do produto e dos fatores de produção foi calculado a partir da média do valor agregado da região. 2. O crescimento médio anual da PTF e a decomposição do crescimento da PTF são resultados do modelo estimado.

registrado neste artigo. Os autores utilizaram o índice de Tornqvist. Como esta pesquisa não utiliza medidas agregadas, mas medidas condicionadas e um nível mais desagregado para análise, diferenças em relação a trabalhos já realizados podem ser justificadas.

Autores como Bragagnolo et al. (2010) e Gasques et al. (2010) verificaram crescimento de PTF para a agropecuária do Brasil e para a maior parte de seus estados. Todavia, esta pesquisa mostrou que, embora a PTF da região Sudeste também tenha crescido, isso não ocorreu com a mesma velocidade entre os diferentes estabelecimentos. Há maiores barreiras para o crescimento da PTF para alguns estabelecimentos.

Diante disso, surgem algumas questões: as fontes de crescimento da PTF, mudança tecnológica e mudança na eficiência técnica podem explicar essa diferença de crescimento entre os produtores da região Sudeste? Ocorreu mudança tecnológica para todos os tamanhos de estabelecimentos? Ocorreu uma melhora na eficiência técnica para todos estes estabelecimentos?

Enquanto a PTF dos estabelecimentos da classe de área 0-5 ha cresceu 0,80\% ao ano entre 1985 e 2006, a PTF dos estabelecimentos da classe 100-500 ha teve aumento de 2,96\%. Esta classe de área representou $27,6 \%$ do valor da produção da região Sudeste em 2006. Os estabelecimentos com menor crescimento de PTF representaram apenas 5,1\% do valor da produção.

As classes de área que alcançaram o maior crescimento de PTF, 100-500 ha e 500 ha e mais, foram as com maior crescimento do produto (Tabela 2). A mão de obra teve redução, exceto para o tamanho 0-5 ha. Este fator de produção é o que menos contribui para o crescimento do produto, conforme os modelos estimados. $\mathrm{O}$ fator de produção que mais favorece o crescimento do produto e que mais teve avanço em todas as classes de área, associado às despesas, cresceu de forma mais rápida na classe de área 500 ha e mais.

Mesmo que as últimas classes de área 100-500 ha e 500 ha e mais tenham atingido maior crescimento de PTF, nota-se que a penúltima classe, 100-500 ha, alcançou elevação mais expressiva. A classe de área 500 ha e mais tem um intervalo aberto e pode compreender estabelecimentos extremamente grandes e improdutivos.

O maior crescimento da PTF dos maiores estabelecimentos é contrário a diversos trabalhos que apontaram uma relação inversa entre produtividade e tamanho de estabelecimento, como Barrett et al. (2010), Carletto et al. (2013) e Henderson (2015), que discutem a maior eficiência ou produtividade entre os menores estabelecimentos.

Henderson (2015), por exemplo, evidencia que pequenos estabelecimentos utilizam mão de obra de forma mais intensiva e não têm custos de contratação como os grandes estabelecimentos. Porém, observou-se, nesta pesquisa, que a média da mão de obra familiar é muito semelhante entre os diferentes tamanhos de estabelecimentos. Supõe-se que os pequenos estabelecimentos da região Sudeste podem não explorar da melhor forma possível o fator de produção que talvez tenham mais acesso, a mão de obra familiar.

A medida de produtividade parcial poderia ter levado a resultados diferentes (Moreira et al., 2007). Este trabalho apresentou a relação entre crescimento da PTF e tamanho de estabelecimentos. Neste caso, não somente a terra, mas todos os fatores de produção, como mão de obra familiar, despesas e estoque de capital, foram 
considerados. Como os maiores estabelecimentos podem ter acesso mais fácil a fatores de produção e a tecnologias, o maior crescimento da PTF pode ser explicado.

A decomposição do crescimento da PTF mostrou que a mudança tecnológica ocorreu para todos os tamanhos de estabelecimentos entre 1985 e 2006. Entretanto, o deslocamento da fronteira de produção, que ocorre pela inserção de novas tecnologias, não foi o mesmo para todas as classes de área. A mudança tecnológica dos menores estabelecimentos, que têm entre $0-5$ ha, foi $5,16 \%$. Já os estabelecimentos que têm entre 100-500 ha alcançaram uma mudança tecnológica duas vezes maior.

A estimativa de outra fonte de crescimento da PTF, mudança na eficiência técnica, foi negativa. Nenhum tamanho de estabelecimento mostrou melhora na eficiência técnica. Um melhor gerenciamento do estabelecimento ou uso dos fatores de produção não foi observado, o que pode ter limitado o maior crescimento de PTF para todos os estabelecimentos estudados. Mesmo os estabelecimentos maiores, que têm entre 100-500 ha e 500 ha e mais, que passaram por maior mudança tecnológica e, consequentemente, maior deslocamento na fronteira de produção e maior crescimento de PTF, apresentaram ineficiência técnica.

Além da criação de tecnologias, segundo Alves et al. (2016), é preciso que os produtores tenham acesso e saibam empregá-las. Conforme os autores, a extensão rural e a assistência técnica podem contribuir para a inclusão de produtores ao processo de adoção tecnológica. O censo agropecuário de 2006 revelou que $11 \%$ das pessoas que dirigem os estabelecimentos não sabem ler e escrever. Observou-se que 69\% dos estabelecimentos não receberam orientação técnica, $19 \%$ receberam ocasionalmente e apenas $12 \%$, regularmente.

Ainda que pequenas propriedades careçam de maior atenção, devido às dificuldades de acesso a fatores de produção e a tecnologias, esta pesquisa apontou que todos os tamanhos de estabelecimentos precisam de maior direcionamento de políticas que levem à redução de ineficiências. Proporcionar condições que levem à melhora na capacidade gerencial do estabelecimento, que possibilitem ao produtor combinar os insumos da melhor forma possível e utilizar as tecnologias desenvolvidas é fundamental para todos os tamanhos de estabelecimentos, mesmo aqueles que têm acesso mais fácil a essas tecnologias.

\section{Conclusões}

Com o modelo de fronteira estocástica de produção foi possível medir o crescimento da PTF segundo o tamanho de estabelecimentos rurais na região Sudeste entre os censos agropecuários de 1985, 1995/ 96 e 2006, assim como decompor este crescimento em mudança tecnológica e mudança na eficiência técnica. Além dos fatores de produção, área, mão de obra, despesas e estoque de capital, outras variáveis que afetam a produtividade foram adicionadas aos modelos, como variáveis de precipitação, solo, custo de transporte, assistência técnica e crédito.

A medida de crescimento da produtividade teve algumas alterações com a inserção destas variáveis. Porém, o comportamento do crescimento da PTF entre os cinco tamanhos de estabelecimentos permaneceu o mesmo, o que indica consistência nos modelos estimados.

As estatísticas descritivas apontaram que a média do produto aumenta com o tamanho do estabelecimento. A média da mão de obra, fator de produção que menos contribui para o aumento do produto, é semelhante entre as classes de área. Diferentemente, a média das despesas, que geram o maior efeito positivo sobre o produto, é maior para os maiores estabelecimentos. Estes têm uma média das despesas 213 vezes maior em comparação à das despesas dos estabelecimentos que têm entre 0-5 ha. Portanto, os maiores estabelecimentos despendem maiores recursos com o fator que mais contribui para o crescimento do produto.

O crescimento do produto foi superior ao dos fatores de produção entre 1985 e 2006 . O crescimento médio anual da PTF na região Sudeste, que passou por um processo de modernização anterior a algumas regiões do País e que esteve relativamente mais próxima da fronteira tecnológica da agricultura brasileira, foi de 3,12\%. A PTF contribuiu para o crescimento do produto agrícola.

Embora o crescimento da PTF tenha sido positivo na região Sudeste, este crescimento não ocorreu com a mesma velocidade entre os diferentes tamanhos de estabelecimentos. Boa parte da literatura discute uma relação inversa entre PTF e tamanho de estabelecimentos. Todavia, não foi essa a relação observada entre crescimento da PTF e tamanho de estabelecimentos nesta pesquisa. As duas últimas classes de área, 100-500 ha e 500 ha e mais, alcançaram maior crescimento de PTF do que as três primeiras classes de área, 0-5 ha, 5-20 ha e 20-100 ha. 
A mudança tecnológica foi a principal fonte de crescimento da produtividade para todos os tamanhos de estabelecimentos. Contudo, essa mudança tecnológica não ocorreu da mesma forma entre os estabelecimentos. A classe de área 100-500 ha passou por uma mudança tecnológica duas vezes maior em comparação à mudança tecnológica que ocorreu na classe de área 0-5 ha. Pode-se afirmar que a criação e a utilização de inovações, principais formas de estimular o crescimento da PTF, não atingem todos os produtores de maneira homogênea.

Mesmo os maiores estabelecimentos, que tiveram maior mudança tecnológica, perderam eficiência técnica. A ineficiência aumentou na região Sudeste entre 1985 e 2006. Nenhuma classe de área mostrou melhora na capacidade gerencial do estabelecimento ou melhor uso dos fatores de produção aliado à mudança tecnológica.

Os menores estabelecimentos não utilizam a mão de obra de forma mais intensiva e não adquirirem vantagens em relação aos maiores estabelecimentos. Embora os estabelecimentos que têm entre 0-5 ha careçam de maior atenção devido à menor mudança tecnológica, à maior dificuldade de acesso a insumos e crédito e ao maior custo de transporte, observou-se que todos os tamanhos de estabelecimentos rurais precisam de políticas que permitam reduzir ineficiências.

Investir em pesquisa e desenvolver tecnologias é necessário, uma vez que a mudança tecnológica é a principal fonte de crescimento da PTF, mas possibilitar que todos os tamanhos de produtores tenham acesso a essa tecnologia levaria a um maior crescimento do produto agrícola.

Os produtores precisam ter maior acesso à informação, à instrução e à educação, para que possam fazer melhor uso destas tecnologias e dos próprios fatores de produção e desenvolver maiores habilidades gerenciais. Neste cenário, a atenção é dada também aos estabelecimentos de grande porte que, mesmo com alta mudança tecnológica, perderam eficiência técnica e poderiam ter alcançado crescimento de PTF ainda maior.

\section{Agradecimentos}

Os autores agradecem pela contribuição de Steven M. Helfand (University of California, Riverside) com a construção de variáveis e disponibilidade de dados. O presente trabalho foi realizado com apoio da Coordenação de Aperfeiçoamento de Pessoal de Nível Superior - Brasil (CAPES) - Código de Financiamento 001.

\section{Referências}

Aigner, D., Lovell, C. A. K., \& Schimidt, P. (1977). Formulation and estimation of stochastic frontier production function models. Journal of Econometrics, 6(1), 21-37.

Ali, D. A., \& Deininger, K. (2014). Is there a farm sizeproductivity relationship in African agriculture? Evidence from Rwanda. Land Economics, 91(2), 317-343.

Alves, E. R. A., Santana, C. A. M., \& Contini, E. (2016). Extensão rural: seu problema não é a comunicação. In J. E. R. Vieira Filho \& J. G. Gasques. Agricultura, transformação produtiva e sustentabilidade (pp. 65-86). Brasília: IPEA.

Assunção, J., \& Chein, F. (2016). Climate change and agricultural productivity in Brazil: future perspectives. Environment and Development Economics, 21(5), 581-602.

Ávila, A. F. D., Garagorry, F., \& Cardoso, C. C. (2013). Produção e produtividade da agricultura brasileira: taxas de crescimento, comparações regionais e seus determinantes. In E. R. A. Alves, G. S. Souza \& E. G. Gomes. Contribuição da Embrapa para o desenvolvimento da agricultura no Brasil (pp. 87-124). Brasília: Embrapa.

Ávila, A. F. D., Romano, L., \& Garagorry, F. Agricultural productivity in Latin America and the Caribbean and sources of growth. In R. E. Pingali \& P. L. Evenson. Handbook of agricultural economics (Vol. 4. pp. 3713-3767). Burlington: Academic Press, 2010.

Banco Central do Brasil-BACEN. (2015). Sistema financeiro nacional. Brasília: BACEN.

Barrett, C. B. (1997). How credible are estimates of peasant allocative, scale, or scope efficiency? A commentary. Journal of International Development, 9(2), 221-229.

Barrett, C. B., Bellemare, M. F., \& Hou, J. Y. (2010). Reconsidering conventional explanations of the inverse productivity-size relationship. World Development, 38(1), 88-97.

Battese, G. E., \& Coelli, T. J. (1992). Frontier production functions, technical efficiency, and panel data: with application to paddy farmers in India. Journal of Productivity Analysis, 3(1), 153-169.

Bragagnolo, C., \& Barros, G. S. C. (2015). Impactos dinâmicos dos fatores de produção e da produtividade sobre a função de produção agrícola. Revista de Economia e Sociologia Rural, 53(1), 31-50. 
Bragagnolo, C., Spolador, H. F. S., \& Barros, G. S. C. (2010). Regional Brazilian agriculture TFP analysis: a stochastic frontier analysis approach. Revista Economia, 11(4), 217-242.

Buainain, A. M., Santana, C. A. M., Silva, F. P., Garcia, J. R., \& Loyola, P. (2014). O tripé da política agrícola brasileira: crédito rural, seguro e Pronaf. In A. M. Buainain, E. Alves, J. M. Silveira \& Z. Navarro. O mundo rural no Brasil do século 21: a formação de um novo padrão agrário e agrícola (pp. 827-864). Brasília: Embrapa.

Carletto, C., Savastano, S., \& Zezza, A. (2013). Fact or artifact: the impact of measurement errors on the farm size-productivity relationship. Journal of Development Economics, 103, 254-261.

Carrer, M. J., \& Souza Filho, H. M. (2016). Economias de escala e eficiência econômica na produção de laranja no estado de São Paulo. Revista de Economia e Sociologia Rural, 54(1), 51-70.

Coelli, T. J., Estache, A., Perelman, S., \& Trujillo, L. (2003). A primer on efficiency measurement for utilities and transport regulators. Washington: The World Bank.

Conceição, J. C. P. R. (2004). Estimação e análise de fronteiras de produção estocásticas. In M. L. D. Santos \& W. C. Vieira. Métodos quantitativos em economia (pp. 523-554). Viçosa: UFV.

Figueiredo, N. M. S., \& Corrêa, A. M. C. J. (2006). Tecnologia na agricultura brasileira: indicadores de modernização no início dos anos 2000 (Texto para discussão, No. 1163, 32 p.). Brasília: IPEA.

Food and Agriculture Organization of the United Nations -FAO. (2000). The state of food and agriculture. Rome: FAO. Recuperado em 2 de agosto de 2017, de www.fao.org

Fundação Getúlio Vargas - FGV. (1985). IBRE. Rio de Janeiro: FGV.

Gasques, J. G., Bastos, E. T., \& Conceição, J. C. R. (2004). Condicionantes da produtividade da agricultura brasileira. Revista de Política Agrícola, 13(3), 73-90.

Gasques, J. G., Bastos, E. T., Bacchi, M. R. P., \& Valdes, C. (2010). Produtividade total dos fatores e transformações da agricultura brasileira: análise dos dados dos censos agropecuários. In J. G. Gasques, J. E. R. Vieira Filho \& Z. Navarro. A agricultura brasileira: desempenho, desafios e perspectivas (pp. 19-44). Brasília: IPEA.

Gasques, J. G., Bastos, E. T., Valdes, C., \& Bacchi, M. R. P. (2012). Produtividade da agricultura brasileira e os efeitos de algumas políticas. Revista de Política Agrícola, 21(3), 83-92.

Gasques, J. G., Bastos, E. T., Valdes, C., \& Bacchi, M. R. P. (2014). Produtividade da agricultura: resultados para o Brasil e estados selecionados. Revista de Política Agrícola, 23(3), 87-98.
Helfand, S. M., \& Levine, E. S. (2004). Farm size and the determinants of productive efficiency in the Brazilian Center-West. Agricultural Economics, 31(2-3), 241-249.

Helfand, S. M., Magalhães, M. M., \& Rada, N. E. (2015). Brazil's agricultural total factor productivity growth by farm size. (Inter-American Development Bank Working Paper Series, No. 609). Washington: IADB. Recuperado em 1 de agosto de 2015, de http: / / www.iadb.org/

Henderson, H. (2015). Considering technical and allocative efficiency in the inverse farm size-productivity relationship. Journal of Agricultural Economics, 66(2), 442-469.

Instituto Brasileiro de Geografia e Estatística - IBGE. (1983). Censo demográfico 1980. Rio de Janeiro: IBGE.

Instituto Brasileiro de Geografia e Estatística - IBGE. (1991). Censo agropecuário 1985. Rio de Janeiro: IBGE.

Instituto Brasileiro de Geografia e Estatística - IBGE. (1994). Censo demográfico 1991. Rio de Janeiro: IBGE.

Instituto Brasileiro de Geografia e Estatística - IBGE. (1998). Censo agropecuário 1995/96. Rio de Janeiro: IBGE, 1998.

Instituto Brasileiro de Geografia e Estatística - IBGE. (2003). Censo demográfico 2000. Rio de Janeiro: IBGE.

Instituto Brasileiro de Geografia e Estatística - IBGE. (2005). Sistema Geodésico Brasileiro. Rio de Janeiro: IBGE.

Instituto Brasileiro de Geografia e Estatística - IBGE. (2012). Censo agropecuário 2006. Rio de Janeiro: IBGE.

Instituto de Economia Agrícola - IEA. (2015). Banco de dados. São Paulo: IEA.

Instituto de Pesquisa Econômica Aplicada - IPEA. (1980). IPEADATA. Rio de Janeiro: IPEA.

Kageyama, A. A. (2008). Desigualdades regionais do desenvolvimento. In A. A. Kageyama. Desenvolvimento rural: conceitos e aplicação ao caso brasileiro (pp. 117-181). Porto Alegre: Editora da UFRGS.

Kalirajan, K. P., Obwona, M. B., \& Zhao, S. (1996). A decomposition of total factor productivity growth: the case of Chinese agricultural growth before and after reforms. American Journal of Agricultural Economics, 78(2), 331-338.

Kumbhakar, S. C., Wang, H., \& Horncastle, A. P. (2015). A practitioner's guide to stochastic frontier analysis using stata. New York: Cambridge University Press.

Lachaud, M. A., Bravo-Ureta, B. E., \& Ludena, C. E. (2015). Agricultural productivity growth in Latin America and the Caribbean and other world regions: an analysis of climatic effects, convergence and catch-up (Inter-American Development Bank Working Paper Series, No. 607). Washington: IADB. Recuperado em 6 de novembro de 2015, de http:/ / www.iadb.org/

Magalhães, M. M., Souza Filho, H. M., Sousa, M. R., Silveira, J. M. F. J., \& Buainain, A. M. (2011). Land reform in NE Brazil: a stochastic frontier production 
efficiency evaluation. Revista de Economia e Sociologia Rural, 49(1), 9-30.

Melo-Becerra, L. A., \& Orozco-Gallo, A. J. (2017). Technical efficiency for Colombian small crop and livestock farmers: a stochastic metafrontier approach for different production systems. Journal of Productivity Analysis, 47(1), 1-16.

Moreira, A. R. B., Helfand, S. M., \& Figueiredo, A. M. R. (2007). Explicando as diferenças na produtividade agrícola no Brasil (Texto para discussão, No. 1254, 31 p.). Rio de Janeiro: IPEA.

Mundlak, Y. (1978). On pooling of time series and cross section data. Econometrica, 46(1), 69-85.

O'Donnell, C. J. (2010). Measuring and decomposing agricultural productivity and profitability change. The Australian Journal of Agricultural and Resource Economics, 54(4), 527-560.
Rada, N. E., \& Buccola, S. T. (2012). Agricultural policy and productivity: evidence from Brazilian censuses. Agricultural Economics, 43(4), 355-367.

Sparovek, G. (2006). Fatores de clima e solo: Brasil. Piracicaba: Departamento de Ciência do Solo, ESALQUSP. Mimeo.

Suri, T. (2011). Selection and comparative advantage in technology adoption. Econometrica, 79(1), 159-209.

Vicente, J. R. (2004). Economic efficiency of agricultural production in Brazil. Revista de Economia e Sociologia Rural, 42(2), 201-222.

Willmott, C. J., \& Matsuura, K. (2001). Terrestrial air temperature and precipitation: monthly and annual time series (1950-1999). Newark: University of Delaware. Recuperado em 11 de agosto de 2016, de climate.geog. udel.edu/ climate/html_pages/README.ghcn_ts.html

World Bank. (2016). World development indicators 2016. Washington: World Bank. Recuperado em 13 de novembro de 2016, de openknowledge.worldbank.org 
Apêndice A. Modelos ${ }^{1}$ de fronteira estocástica de produção para a macrorregião Sudeste

\begin{tabular}{|c|c|c|c|c|c|c|c|c|c|c|}
\hline & $\mathrm{CD}$ & CD i.UF & CD CRE & $\begin{array}{l}\text { CD CRE } \\
\text { + Clima }\end{array}$ & $\begin{array}{l}\text { CD CRE } \\
+ \text { Clima } \\
\text { + Solo }\end{array}$ & $\begin{array}{l}\text { CD CRE } \\
+ \text { Clima } \\
+ \text { Transp }\end{array}$ & $\begin{array}{l}\text { CD CRE } \\
+ \text { Clima } \\
\text { + Solo } \\
+ \text { Transp }\end{array}$ & $\begin{array}{c}\text { CD CRE } \\
+ \text { Clima } \\
+ \\
\text { Política }\end{array}$ & $\begin{array}{c}\text { CD CRE } \\
+ \text { Clima } \\
+ \text { Solo } \\
+ \\
\text { Política }\end{array}$ & $\begin{array}{c}\text { CD CRE } \\
+ \text { Clima } \\
+ \text { Solo } \\
+ \text { Transp } \\
+ \\
\text { Política }\end{array}$ \\
\hline & 1 & 2 & 3 & 4 & 5 & 6 & 7 & 8 & 9 & 10 \\
\hline \multicolumn{11}{|l|}{$\mathbf{Y}$} \\
\hline Área & $0.168^{* *}$ & $0.190^{* *}$ & $0.653^{* *}$ & $0.552^{* *}$ & $0.559^{* *}$ & $0.552^{* *}$ & $0.559^{* *}$ & $0.544^{* *}$ & $0.551^{* *}$ & $0.551^{* *}$ \\
\hline Mão de obra & $-0.095^{* *}$ & $-0.068^{* *}$ & $-0.042^{*}$ & $-0.068^{* *}$ & $-0.067^{* *}$ & $-0.068^{* *}$ & $-0.068^{* *}$ & $-0.067^{* *}$ & $-0.067^{* *}$ & $-0.067^{* *}$ \\
\hline Despesas & $0.627^{* *}$ & $0.614^{* *}$ & $0.474^{* *}$ & $0.498^{* *}$ & $0.498^{* *}$ & $0.499^{* *}$ & $0.498^{* *}$ & $0.500^{* *}$ & $0.500^{* *}$ & $0.500^{* *}$ \\
\hline Capital & $0.150^{* *}$ & $0.124^{* *}$ & $0.155^{* *}$ & $0.180^{* *}$ & $0.177^{* *}$ & $0.180^{* *}$ & $0.177^{* *}$ & $0.179^{* *}$ & $0.176^{* *}$ & $0.176^{* *}$ \\
\hline Tempo & $0.046^{* *}$ & $0.045^{* *}$ & $0.050^{* *}$ & $0.094^{* *}$ & $0.095^{* *}$ & $0.094^{* *}$ & $0.095^{* *}$ & $0.095^{* *}$ & $0.096^{* *}$ & $0.096^{* *}$ \\
\hline Área_média & & & $-0.547^{* *}$ & $-0.406^{* *}$ & $-0.414^{* *}$ & $-0.398^{* *}$ & $-0.409^{* *}$ & $-0.395^{* *}$ & $-0.403^{* *}$ & $-0.399^{* *}$ \\
\hline $\begin{array}{l}\text { Mão de obra_ } \\
\text { média }\end{array}$ & & & $-0.102^{* *}$ & 0.007 & -0.011 & 0.009 & -0.005 & 0.017 & -0.002 & 0.002 \\
\hline Despesas_média & & & $0.249^{* *}$ & $0.215^{* *}$ & $0.215^{* *}$ & $0.208^{* *}$ & $0.211^{* *}$ & $0.209^{* *}$ & $0.209^{* *}$ & $0.206^{* *}$ \\
\hline Capital_média & & & $-0.042^{*}$ & $-0.111^{* *}$ & $-0.101^{* *}$ & $-0.110^{* *}$ & $-0.102^{* *}$ & $-0.110^{* *}$ & $-0.100^{* *}$ & $-0.101^{* *}$ \\
\hline ES & & 0.035 & & & & & & & & \\
\hline RJ & & 0.042 & & & & & & & & \\
\hline SP & & $0.172^{* *}$ & & & & & & & & \\
\hline 1.pp_jan-mar ${ }^{3}$ & & & & 0.025 & 0.005 & 0.035 & 0.011 & 0.026 & 0.007 & 0.012 \\
\hline 2.pp_jan-mar & & & & $-0.063^{* *}$ & $-0.073^{* *}$ & $-0.060^{* *}$ & $-0.071^{* *}$ & $-0.065^{* *}$ & $-0.074^{* *}$ & $-0.072^{* *}$ \\
\hline 4.pp_jan-mar & & & & $-0.080^{* *}$ & $-0.083^{* *}$ & $-0.079^{* *}$ & $-0.083^{* *}$ & $-0.077^{* *}$ & $-0.081^{* *}$ & $-0.080^{* *}$ \\
\hline 5.pp_jan-mar & & & & $0.110^{* *}$ & $0.105^{* *}$ & $0.110^{* *}$ & $0.106^{* *}$ & $0.110^{* *}$ & $0.104^{* *}$ & $0.105^{* *}$ \\
\hline 1.pp_abr-jun & & & & $0.175^{* *}$ & $0.168^{* *}$ & $0.178^{* *}$ & $0.170^{* *}$ & $0.173^{* *}$ & $0.166^{* *}$ & $0.168^{* *}$ \\
\hline 2.pp_abr-jun & & & & $0.055^{* *}$ & $0.047^{* *}$ & $0.054^{* *}$ & $0.047^{* *}$ & $0.059^{* *}$ & $0.051^{* *}$ & $0.050^{* *}$ \\
\hline 4.pp_abr-jun & & & & -0.022 & -0.026 & -0.025 & -0.027 & -0.021 & -0.026 & -0.027 \\
\hline 5.pp_abr-jun & & & & $-0.131^{* *}$ & $-0.123^{* *}$ & $-0.130^{* *}$ & $-0.124^{* *}$ & $-0.126^{* *}$ & $-0.119^{* *}$ & $-0.119^{* *}$ \\
\hline 1.pp_jul-set & & & & $-0.424^{* *}$ & $-0.376^{* *}$ & $-0.417^{* *}$ & $-0.374^{* *}$ & $-0.423^{* *}$ & $-0.376^{* *}$ & $-0.374^{* *}$ \\
\hline 2.pp_jul-set & & & & $-0.170^{* *}$ & $-0.148^{* *}$ & $-0.171^{* *}$ & $-0.149^{* *}$ & $-0.164^{* *}$ & $-0.143^{* *}$ & $-0.144^{* *}$ \\
\hline 4.pp_jul-set & & & & $0.161^{* *}$ & $0.189^{* *}$ & $0.156^{* *}$ & $0.185^{* *}$ & $0.157^{* *}$ & $0.184^{* *}$ & $0.180^{* *}$ \\
\hline 5.pp_jul-set & & & & -0.002 & 0.027 & -0.004 & 0.024 & -0.004 & 0.024 & 0.022 \\
\hline 1.pp_out-dez & & & & $0.481^{* *}$ & $0.486^{* *}$ & $0.481^{* *}$ & $0.486^{* *}$ & $0.471^{* *}$ & $0.476^{* *}$ & $0.476^{* *}$ \\
\hline 2.pp_out-dez & & & & $0.228^{* *}$ & $0.232^{* *}$ & $0.232^{* *}$ & $0.233^{* *}$ & $0.221^{* *}$ & $0.226^{* *}$ & $0.227^{* *}$ \\
\hline 4.pp_out-dez & & & & $0.037^{* *}$ & $0.036^{* *}$ & $0.038^{* *}$ & $0.036^{* *}$ & $0.035^{* *}$ & $0.033^{*}$ & $0.034^{* *}$ \\
\hline 5.pp_out-dez & & & & $0.073^{* *}$ & $0.053^{* *}$ & $0.071^{* *}$ & $0.054^{* *}$ & $0.071^{* *}$ & $0.050^{*}$ & $0.052^{* *}$ \\
\hline $\begin{array}{l}\text { Potencial de } \\
\text { Mecanização }\end{array}$ & & & & & $-0.009^{* *}$ & & $-0.007^{* *}$ & & $-0.009^{* *}$ & $-0.008^{* *}$ \\
\hline $\begin{array}{l}\text { Capacidade de } \\
\text { Drenagem }\end{array}$ & & & & & 0.004 & & 0.005 & & 0.003 & 0.004 \\
\hline Fertilidade & & & & & 0.006 & & $0.007^{*}$ & & 0.005 & 0.006 \\
\hline Altitude & & & & & $-0.056^{* *}$ & & $-0.053^{* *}$ & & $-0.054^{* *}$ & $-0.052^{* *}$ \\
\hline Custo até a Capital & & & & & & $-0.027^{* *}$ & $-0.017^{*}$ & & & $-0.015^{*}$ \\
\hline
\end{tabular}

Fonte: Resultados da pesquisa.

Notas: 1. As observações foram ponderadas pela participação no valor da produção. 2. ${ }^{*} \mathrm{p}<0,05$; ${ }^{* *} \mathrm{p}<0,01$. 3. Variáveis de precipitação para cada classe de percentil e trimestre. 
Apêndice A. Continuação...

\begin{tabular}{|c|c|c|c|c|c|c|c|c|c|c|}
\hline & CD & CD i.UF & CD CRE & $\begin{array}{l}\text { CD CRE } \\
\text { + Clima }\end{array}$ & $\begin{array}{l}\text { CD CRE } \\
\text { + Clima } \\
\text { + Solo }\end{array}$ & $\begin{array}{l}\text { CD CRE } \\
\text { + Clima } \\
+ \text { Transp }\end{array}$ & $\begin{array}{l}\text { CD CRE } \\
\text { + Clima } \\
\text { + Solo } \\
\text { + Transp }\end{array}$ & $\begin{array}{c}\text { CD CRE } \\
+ \text { Clima } \\
+ \\
\text { Política }\end{array}$ & $\begin{array}{c}\text { CD CRE } \\
+ \text { Clima } \\
+ \text { Solo } \\
+ \\
\text { Política }\end{array}$ & $\begin{array}{c}\text { CD CRE } \\
+ \text { Clima } \\
+ \text { Solo } \\
+ \text { Transp } \\
+ \\
\text { Política }\end{array}$ \\
\hline & 1 & 2 & 3 & 4 & 5 & 6 & 7 & 8 & 9 & 10 \\
\hline $\begin{array}{l}\text { A ssistência } \\
\text { Técnica }\end{array}$ & & & & & & & & 0.002 & 0.004 & 0.002 \\
\hline Crédito & & & & & & & & $0.313^{* *}$ & $0.306^{* *}$ & $0.301^{* *}$ \\
\hline _cons & $2.489^{* *}$ & $2.669^{* *}$ & $2.186^{* *}$ & $1.963^{* *}$ & $2.224^{* *}$ & $2.159^{* *}$ & $2.322^{* *}$ & $1.978^{* *}$ & $2.250^{* *}$ & $2.334^{* *}$ \\
\hline$\eta$ & $-0.048^{* *}$ & $-0.048^{* *}$ & $-0.044^{* *}$ & $-0.079^{* *}$ & $-0.080^{* *}$ & $-0.079 * *$ & $-0.080^{* *}$ & $-0.080^{* *}$ & $-0.081^{* *}$ & $-0.082^{* *}$ \\
\hline$\gamma$ & 0.326 & 0.308 & 0.304 & 0.492 & 0.495 & 0.492 & 0.495 & 0.498 & 0.501 & 0.500 \\
\hline Sigma_U & 0.397 & 0.382 & 0.372 & 0.508 & 0.510 & 0.508 & 0.509 & 0.513 & 0.515 & 0.514 \\
\hline Sigma_V & 0.572 & 0.573 & 0.564 & 0.516 & 0.515 & 0.516 & 0.515 & 0.515 & 0.514 & 0.514 \\
\hline $\mathrm{Ll}$ & $-15,725$ & $-15,637$ & $-15,411$ & $-14,722$ & $-14,688$ & $-14,715$ & $-14,685$ & $-14,710$ & $-14,677$ & $-14,675$ \\
\hline Converged & 1 & 1 & 1 & 1 & 1 & 1 & 1 & 1 & 1 & 1 \\
\hline $\mathrm{N}$ & 18,126 & 18,126 & 18,126 & 18,126 & 18,126 & 18,126 & 18,126 & 18,126 & 18,126 & 18,126 \\
\hline
\end{tabular}

Fonte: Resultados da pesquisa.

Notas: 1. As observações foram ponderadas pela participação no valor da produção. 2 . ${ }^{*} \mathrm{p}<0,05$; ${ }^{* *} \mathrm{p}<0,01$. 3. Variáveis de precipitação para cada classe de percentil e trimestre. 